\title{
Expression and Activity of Cyclin-Dependent Kinases and Glycogen Synthase Kinase-3 during NT2 Neuronal Differentiation
}

\author{
Marie Gompel ${ }^{a}$ Cathia Soulié ${ }^{b}$ Irène Ceballos-Picot ${ }^{b}$ Laurent Meijer ${ }^{a}$ \\ aCNRS, Cell Cycle Group, Station Biologique, Roscoff, and bINSERM U 383, Génétique, Chromosomes et Cancer, \\ Hôpital Necker, Paris, France
}

\section{Key Words}

Cyclin-dependent kinase · Glycogen synthase kinase • GSK-3 $\beta$ - Paullones · Purines · Kinase inhibitor · Alzheimer's disease

\begin{abstract}
In the presence of retinoic acid undifferentiated NT2 cells turn into terminally differentiated hNT (or NT2N) neurons within 5 weeks. We have used this in vitro cellular model to investigate the changes in expression and activity of cyclin-dependent kinases (CDKs) and glycogen synthase kinase-3 (GSK-3) during this neuronal differentiation process. We here show that CDK $1 / 2$ protein level and kinase activity sharply decrease during the NT2 $\rightarrow$ hNT transition. In contrast, the activity of CDK5/ p35 dramatically increases, probably as a result of an enhanced expression of p35 in a stable CDK5 level background. GSK-3 activity increases modestly during the differentiation of hNT cells, and this event correlates with enhanced expression of each of the three GSK-3 isoforms. Pharmacological inhibitors of CDKs and GSK-3 lead to a dose-dependent decrease in cell viability.
\end{abstract}

Copyright $\odot 2004$ S. Karger AG, Basel

\section{Introduction}

Phosphorylation of serine, threonine and tyrosine residues is the most common post-translational modification used by cells to regulate the function of proteins. The reversible transfer of a phosphate on defined sites of proteins promotes variations of their biological activity: by increasing or decreasing their susceptibility to degradation, by controlling their sub-cellular localization or their ability to interact with other proteins [1].

Neuronal differentiation is a complex process. It is characterized by molecular events leading to the specific, physiological and morphological properties of nerve cells.

One of the main modifications is certainly cell cycle arrest leading to post-mitotic neurons blocked in the $G_{0}$ phase of the cell cycle. The cell cycle is strictly regulated by a family of serine/threonine kinases, the cyclin-dependent kinases (CDKs). Their activity is dependent upon their association with cyclins. $13 \mathrm{CDKs}$ and 25 cyclins have been identified so far. CDK2/cyclin $\mathrm{A}$ or $\mathrm{E}$ and CDK1/cyclin B control the G1/S and the G2/M transitions of the cell cycle, respectively. Even though CDKs were initially identified as cell cycle regulators, they also play a key role in transcription, muscular and neural functions, differentiation and apoptosis. CDK5 is essentially

L. Meijer

CNRS, Cell Cycle Group, Station Biologique

BP 74

FR-29682 Roscoff Cedex (France)

Tel. +332982923 39, Fax +332982923 42, E-Mail meijer@sb-roscoff.fr 
active in brain and plays a pivotal role in neuronal functions [2]. To be active, CDK 5 requires its association with a non-cyclin activator protein, $\mathrm{p} 35$ or the close homologue p39. As an active complex, it can control neurite outgrowth, neuron migration and metabotropic glutamate receptor and dopamine signaling pathways [for review, see 3].

Glycogen synthase kinase-3 (GSK-3) is a serine/ threonine kinase present, in mammals, under two different genes encoding two closely related isoforms, GSK-3 $\alpha$ and GSK- $3 \beta$ (molecular weights of 51 and $47 \mathrm{kD}$, respectively). GSK-3 was originally identified as a negative regulator of glycogen synthase [4], but more recently it appeared to be involved in number of different signaling pathways [5]. It is a key element of the Wnt/Wingless pathway known to control early cell fate decisions and embryonic patterning. Some recent studies suggest that Wnt-7a signaling plays a role in the formation of neuronal connections in the cerebellum. It induces axonal remodeling by inhibiting the activity of GSK-3 $\beta$ [6]. GSK-3 $\beta$ directly phosphorylates several microtubule-associated proteins (MAPs) such as Tau, MAP-1B and MAP-2, involved in microtubule stabilization. Wnt-7a induces a decrease in the GSK- $3 \beta$ phosphorylated form of MAP-1B in cerebellar development. It has been shown that MAP$1 \mathrm{~B}$ phosphorylation by GSK-3 $\beta$ is induced during PC12 cell differentiation [7]. The phosphorylation of MAP-1B is paralleled by the appearance of a novel GSK-3 $\beta$ isoform characterized by a reduced mobility on SDS-PAGE in response to NGF. More recently, this novel isoform has been identified as an alternative spliced isoform of GSK$3 \beta$ named GSK-3 $\beta 2$ [8].

Protein kinase deregulation is a hallmark in number of neurodegenerative disorders. In Alzheimer's disease, GSK-3, CDK5 and other protein kinases like PKA, PKB, MARK or CK1 are responsible for the hyperphosphorylation of Tau. This results in a reduction of its ability to bind microtubules and to the disruption of the cytoskeleton. In the past decades, it became obvious that these 'Tau protein kinases' constitute promising pharmacological targets. Research efforts have been made to discover chemical compounds that could inhibit these kinases for therapeutic applications.

In this study, we have focused our work on several protein kinases during neuronal differentiation. The expression and activity of some CDKs and GSK-3 were characterized during the differentiation process of the human teratocarcinoma cell line (NT2). NT2 cells have the ability to differentiate into postmitotic neurons (NT2N or $\mathrm{hNT}$ ) following retinoic acid treatment $[9,10]$. The effects of several protein kinase inhibitors were also tested on both undifferentiated NT2 cells and differentiated hNT cells. The inhibitors belonging to the purine family do not exhibit any crucial difference in their cellular effects on NT2 undifferentiated cells and hNT post-mitotic neurons. In contrast, alsterpaullone which inhibits both CDKs and GSK-3 (with higher selectivity for GSK-3) is more potent on NT2 than on hNT cells.

\section{Material and Methods}

\section{NT2 Differentiation}

Clonal human NT2 teratocarcinoma cells were obtained from Stratagene (La Jolla, Calif., USA) and maintained in Dulbecco's modified Eagle medium:nutrient mixture F-12 with $L$-glutamine (DMEM-F12) (BIO Whittaker) supplemented with 5\% fetal bovine serum (FBS; BIO Whittaker) and containing penicillin $(20 \mathrm{UI} / \mathrm{ml})$ and streptomycin $(20 \mu \mathrm{g} / \mathrm{ml}$; BIO Whittaker $)$ in a $37^{\circ} \mathrm{C}$ incubator with $5 \% \mathrm{CO}_{2}$.

For neuronal differentiation, the Pleasure method modified by Soulié has been used. Briefly, $2.5 \times 10^{6}$ cells per $75 \mathrm{~cm}^{2}$ flask were seeded and maintained in DMEM-F12 supplemented with 10\% FBS and $10 \mu M$ retinoic acid (RA; Sigma). The growth medium was changed three times a week. Following treatment with RA, the cells were reseeded at 1:6 (reseed 1) and cultured for 2 days in DMEM/ F12 with $10 \%$ FBS, penicillin $(20 \mathrm{UI} / \mathrm{ml})$ and streptomycin $(20 \mu \mathrm{g} /$ $\mathrm{ml}$ ) to improve mechanical dislodgment during the selection process. The hNT cells were selected by a differential trypsinization step (reseed 2), during which the cells were incubated with trypsin-EDTA for $1 \mathrm{~min}$ and the flask was struck twice with the palm of the hand. The cells were collected by centrifugation and reseeded (reseed 2) on dishes previously coated with poly- $D$-lysine $(10 \mu \mathrm{g} / \mathrm{ml}, 2 \mathrm{~h}$; Sigma) and then with the growth factor-reduced Matrigel (Becton Dickinson; following the manufacturer's instructions). To eliminate any non-neuronal cells, the culture was subsequently incubated in DMEM/F12 serum-free medium containing penicillin $(20 \mathrm{IU} / \mathrm{ml})$, streptomycin $(20 \mu \mathrm{g} / \mathrm{ml})$, mitotic inhibitors $(10 \mu M$ fluorodeoxyuridine, $10 \mu M$ uridine and $1 \mu M$ cytosine arabinoside) and a mixture of salt and hormones $(25 \mu \mathrm{g} / \mathrm{ml}$ insulin, $100 \mu \mathrm{g} / \mathrm{ml}$ transferrin, $20 \mathrm{n} M$ progesterone, $60 \mu M$ putrescine, $30 \mathrm{n} M$ sodium selenite) until treatment or collecting. Cells were collected by trypsinisation every week during retinoic acid treatment.

\section{Immunoblotting}

Cells from cultures exposed to retinoic acid from 0 to 5 weeks and hNT, 3 days after the second replate, were washed once with phosphate-buffered saline (PBS) and scraped into PBS prior to affinitychromatography experiment or scraped into sodium dodecyl sulfate polyacrylamide gel electrophoresis (SDS-PAGE) sample buffer. Protein samples were loaded and run on 10\% SDS-polyacrylamide gels, followed by a transfer onto nitrocellulose membranes (Schleicher \& Schuell). Blots were blocked in Tris-buffered saline-Tween (TBS-T: Tris- $\mathrm{HCl} \mathrm{pH} 7.4,150 \mathrm{mM} \mathrm{NaCl}, 5 \%$ Tween) plus $5 \%$ dry non-fat milk for $1 \mathrm{~h}$ at room temperature. Antibodies and dilutions were as follows: CDK5 C-8 (Santa Cruz Sc-173) 1:500, p35 C-19 (Santa Cruz Sc-820) 1:300, PSTAIRE (Sigma) 1:1,000, GSK-3 $\alpha \beta$ (Stressgen KAM-ST002C) 1:1,000. Membranes were then washed with TBS-T 
four times for $15 \mathrm{~min}$, incubated with peroxidase-linked secondary antibody (Bio-Rad) $(1: 5,000)$ in TBS-T for $1 \mathrm{~h}$ at room temperature and washed four times for $15 \mathrm{~min}$ in TBS-T. Blots were then developed with chemoluminescent reagent.

For NSE and MAP-2 Western blotting, protein samples $(5 \mu \mathrm{g})$ were run on NuPAGE 4-12\% Bis-Tris gels (Invitrogen), electroblotted onto nitrocellulose membranes (Hybond $\mathrm{C}$ Extra) and probed with antibodies overnight at $4{ }^{\circ} \mathrm{C}$ after a treatment with $5 \%$ skimmed dried milk in PBST $(0.005 \%$ PBS (v/v) in Tween 20$)$. The primary antibodies in PBST were used at the following dilutions: NSE (clone 1C1) 1:1,000; MAP-2 (Sigma) 1:500. The binding of the primary antibody was detected with horseradish peroxidase conjugated antiIgG secondary antibody followed by ECL (Amersham Biosciences) detection.

\section{GSK-3 Affinity Purification and Kinase Assay}

GSK-3 affinity purification and kinase assay were performed as described [14]. Briefly, cells were sonicated in homogenization buffer (60 m $M$ ß-glycerophosphate, $15 \mathrm{~m} M$ p-NPP, $25 \mathrm{~m} M$ Mops, $\mathrm{pH}$ 7.2, $15 \mathrm{~m} M \mathrm{MgCl}_{2}, 0.5 \mathrm{~m} M$ DTT, $1 \mathrm{~m} M$ NaVanadate, $1 \mathrm{~m} M \mathrm{NaF}, 1 \mathrm{~m} M$ diNa-phenylphosphate, $10 \mu \mathrm{g}$ leupeptin $/ \mathrm{ml}, 10 \mu \mathrm{g}$ aprotinin $/ \mathrm{ml}$, $10 \mu \mathrm{g} \mathrm{SBTI} / \mathrm{ml}, 100 \mu M$ benzamidine), centrifuged at $12,000 \mathrm{rpm}$ for $10 \mathrm{~min}$ at $4^{\circ} \mathrm{C}$, and the supernatant was collected. $150 \mu \mathrm{g}$ of total proteins quantified with the Bio-Rad Bradford protein quantification assay were incubated with $10 \mu \mathrm{l}$ of axin-Sepharose beads for 30 min under constant rotation at $4^{\circ} \mathrm{C}$. Beads are washed 3 times with bead buffer followed by two washes with kinase buffer. GSK-3 affinity-purified or crude extract corresponding to $100 \mu \mathrm{g}$ of total proteins (from the supernatant) was assayed for GSK-3 activity in kinase buffer, at $30^{\circ} \mathrm{C}$ in presence of $40 \mu M$ GS- 1 (substrate), $15 \mu M\left[\gamma_{-}{ }^{33} \mathrm{P}\right] \mathrm{ATP}$ $(3,000 \mathrm{Ci} / \mathrm{mmol} ; 1 \mathrm{mCi} / \mathrm{ml})$ in a final volume of $30 \mu \mathrm{l}$. After $10 \mathrm{~min}$ incubation at $30^{\circ} \mathrm{C}, 25-\mu 1$ aliquots were spotted onto Whatman P81 phosphocellulose paper and counted in a Packard counter.

Beads were washed once with bead buffer and $25 \mu \mathrm{l}$ of Laemmli sample buffer were added. The affinity purified proteins and $100 \mu \mathrm{g}$ of total proteins from crude extract were run in 10\% SDS/polyacrylamide gels. Immunoblotting was performed as explained in the 'Immunoblotting' section.

\section{CDK5 Activity}

After pre-clearing on rabbit serum (DAKO) conjugated to Immunopure immobilized recomb ${ }^{\circledR}$ protein A (Pierce), $500 \mu \mathrm{g}$ of proteins in homogenisation buffer were incubated with $5 \mu$ lof anti-CDK 5 C-8 antibody agarose conjugate (Santa Cruz sc-173AC) under constant rotation for $1 \mathrm{~h}$ at $4{ }^{\circ} \mathrm{C}$. The matrix was washed 3 times with bead buffer and once with assay buffer $(60 \mathrm{~m} M \beta$-glycerophosphate, $15 \mathrm{~m} M$ p-NPP, $25 \mathrm{~m} M$ Mops, pH 7.2, $15 \mathrm{~m} M \mathrm{MgCl}_{2}, 5 \mathrm{~m} M$ EGTA, $0.5 \mathrm{~m} M$ DTT, $1 \mathrm{~m} M$ NaVanadate, $1 \mathrm{~m} M$ diNa-phenylphosphate). The kinase activity was assayed in assay buffer, with $1 \mathrm{mg}$ histone $\mathrm{H} 1$ per $\mathrm{ml}$ in presence of $15 \mu M\left[\gamma_{-}{ }^{33} \mathrm{P}\right] \mathrm{ATP}(3,000 \mathrm{Ci} / \mathrm{mmol} ; 1 \mathrm{mCi} / \mathrm{ml})$ in a final volume of $30 \mu \mathrm{l}$. After $30 \mathrm{~min}$ incubation at $30^{\circ} \mathrm{C}, 30 \mu \mathrm{l}$ of Laemmli sample buffer was added to stop the reaction. After denaturation, samples were analyzed by $10 \%$ SDS-PAGE. Radioactivity incorporation was detected with a Storm phosphoimager (Molecular Dynamics, Sunnyvale, Calif., USA) and quantified with ImageQuaNT software (Molecular Dynamics).

CDK1/2 Affinity Purification and Activity

Active CDK1 and CDK2 were purified from $500 \mu \mathrm{g}$ of proteins in homogenization buffer on p $^{\text {CKShs1 }}$-Sepharose beads according to
Azzi et al. [13]. The kinase activity was assayed in assay buffer as described for CDK5. After $10 \mathrm{~min}$ incubation at $30^{\circ} \mathrm{C}, 25-\mu \mathrm{l}$ aliquots of the supernatant were spotted onto Whatman P81 phosphocellulose paper and, after several washes, counted in a Packard counter.

Beads were washed once with bead buffer and $25 \mu \mathrm{l}$ of Laemmli sample buffer were added. The affinity-purified proteins were run in $10 \%$ SDS/polyacrylamide gels. Immunoblotting was performed with the PSTAIRE antibody.

\section{Cell Treatments}

Exponentially growing cells were incubated for $24 \mathrm{~h}$ with various inhibitors (stock solution dissolved in dimethyl sulfoxide; DMSO). To quantify cell viability, inhibition of reduction of cellular 3-(4,5dimethylthiazol-2-yl)-2,5-diphenyltetrazolium-bromide (MTT) to MTT formazan was measured [29]. Following exposure to the drugs, cells were incubated with MTT $(0.5 \mathrm{mg} / \mathrm{ml}$ fresh medium $)$ at $37^{\circ} \mathrm{C}$ for $1 \mathrm{~h}$. The formazan products were dissolved in DMSO and quantified by measuring absorbance at $562 \mathrm{~nm}$.

\section{Results}

\section{Induction of hNT Differentiation from NT2 Cells by Retinoic Acid}

Throughout this study we have made use of the NT2/ hNT model, a convenient system to investigate morphological and biochemical events occurring in neuronal cells during differentiation $[9,10]$. Following the addition of retinoic acid (RA), and after only 5 weeks of culture owing to the modified method, we obtained a cell population of $90 \%$ hNT neurons. Phase-contrast microscopy of differentiating cells showed that many of the cells developed processes. Most of the hNT cells displayed a morphology typical of neurons and extensive neuron networks gradually developed 5 days following the second reseeding (fig. 1a). The presence of differentiated CNS neuronal markers provides further evidence for neuronal differentiation. MAP-2 is the major microtubule-associated protein in the brain [11]. Analysis of the production of MAP-2 at different stages during the differentiation process showed the apparition of a $280-\mathrm{kD}$ form after 3 weeks of differentiation (MAP-2A and MAP-2B, similarly sized). After 5 weeks of RA treatment, the quantity of the $280 \mathrm{kD}$ form was higher than that of the 3 or 4 weeks. The use of the anti-NSE (neuronal-specific enolase) monoclonal antibody, which only detects gamma enolase in human brain homogenates, showed that RA-treated NT2 cultures upregulate the production of NSE. Serum deprivation coupled with hormone supplementation, leading to an enrichment in neurons, was associated with an increase in NSE production (fig. 1b). 

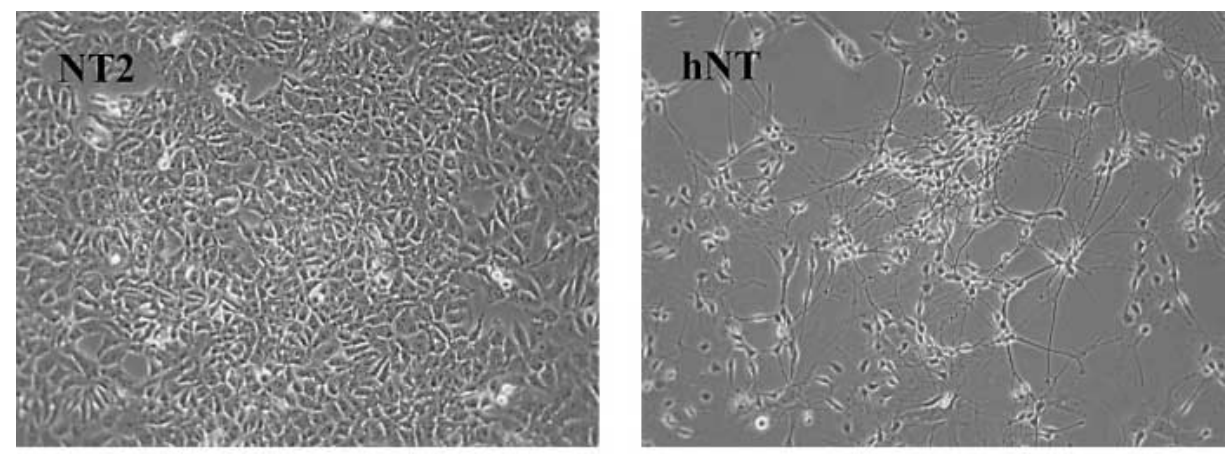

Fig. 1. Under retinoic acid treatment, NT2 differentiate into postmitotic hNT neurons. Differentiation of NT2 cells using the method described by Pleasure et al. [10] and modified by Soulié, results in hNT neurons after 5 weeks of treatment. Phase-contrast photomicrographs (a) show the morphological changes that occur during the transition of NT2 cells to hNT neurons. Equal amounts of total proteins from lysates of untreated parental NT2 cells, RA-treated NT2 and neuronally differentiated cells $(\mathrm{hNT})(\mathrm{d} 6, \mathrm{~d} 15)$ were electrophoretically separated, transferred to nitrocellulose sheets and labeled with anti MAP-2, and anti NSE (b). The 280-kD MAP-2 protein was detected after 3 weeks of RA treatment and in hNT neurons. An increase in the amount of the $47-\mathrm{kD}$ protein, corresponding to NSE, was demonstrated during the RA treatment and this band was also detected in hNT neurons.

\section{CDKs during Neuronal Differentiation}

NT2 cells were thus exposed to $10 \mu M$ retinoic acid for 5 weeks and samples were collected at weekly intervals for Western blotting detection of CDKs and for kinase assays as described in the Material and Methods section (fig. 2). Since CDK $5 / \mathrm{p} 35$ plays a pivotal role in neuronal development [12], the protein kinase CDK 5 was first analyzed at various stages of NT $2 \rightarrow \mathrm{hNT}$ differentiation (fig. $2 \mathrm{a}$ ). The protein level of CDK5 gradually but modestly increased during differentiation (fig. 2a, left panel). A maximal 1.6fold increase was detected after 5 weeks. In contrast, the expression of $\mathrm{p} 35$ could be detected only at the late stages of neuronal differentiation and was not observed at all in untreated NT2 cells. The increase of $\mathrm{p} 35$ protein level was substantial, reaching 17.5-fold after 5 weeks. This increased p35 level was closely accompanied by a dramatic 10-fold increase in CDK5 activity, assayed following immunoprecipitation (fig. 2a, left). The association of the CDK5 to its activator protein $\mathrm{p} 35$ and thus the expression of p35 is crucial for the kinase activity.

We next analyzed the status of the two cell cycle regulators CDK1 and CDK2 during neuronal differentiation (fig. 2b). The levels of activity and expression of these kinases were evaluated after affinity chromatography pu-

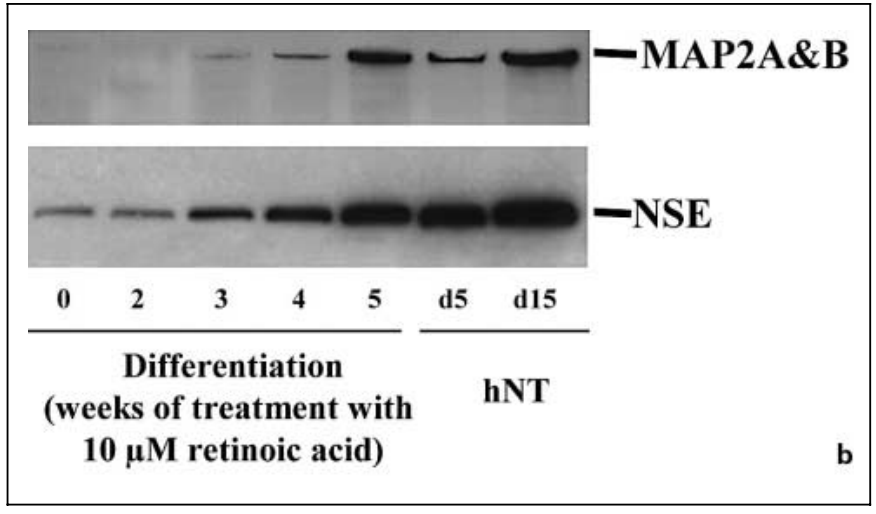

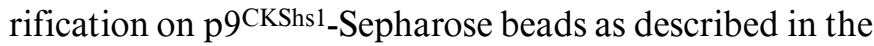
'Material and Methods' section. This method allows a rapid and extensive concentration and purification of active CDK1/CDK2 [13]. The expression levels of CDK1 and 2 were evaluated by Western blot analysis using an antibody directed against an epitope shared by CDK1 and CDK2, the so-called PSTAIRE motif (fig. 2b, left panel). During the NT2 $\rightarrow$ hNT differentiation, a modest decrease in CDK1/CDK2 expression was observed. In contrast, the kinase activity of CDK1/CDK2 decreased drastically (at least by 90\%) 14.4-fold (fig. 2b, right panel). CDK1/2 activity thus displays a pattern opposite to that of CDK5 activity.

\section{GSK-3 during NT2 Differentiation}

We next characterized the GSK-3 kinase during neuronal differentiation (fig. 3). We therefore made use of a method which allows the affinity purification of active GSK-3 isoforms on an immobilized axin fragment and the subsequent determination of their global catalytic activity using the synthetic phosphopeptide GS-1 [14]. Western blot analysis of cells during the 5 week NT2 $\rightarrow$ hNT differentiation revealed a general increase of GSK-3 protein expression, whether GSK-3 $\alpha$, GSK-3 $\beta 1$ or 


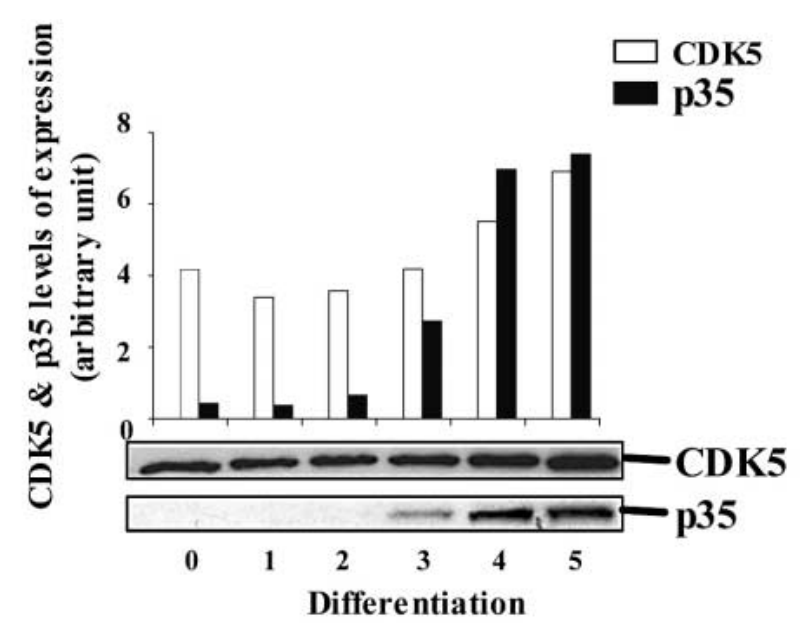

a (weeks of treatment with $10 \mu \mathrm{M}$ retinoic acid)

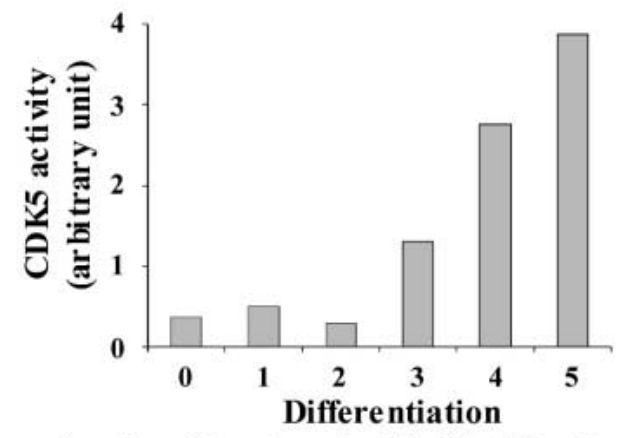

(weeks of treatment with $10 \mu \mathrm{M}$ retinoic acid)
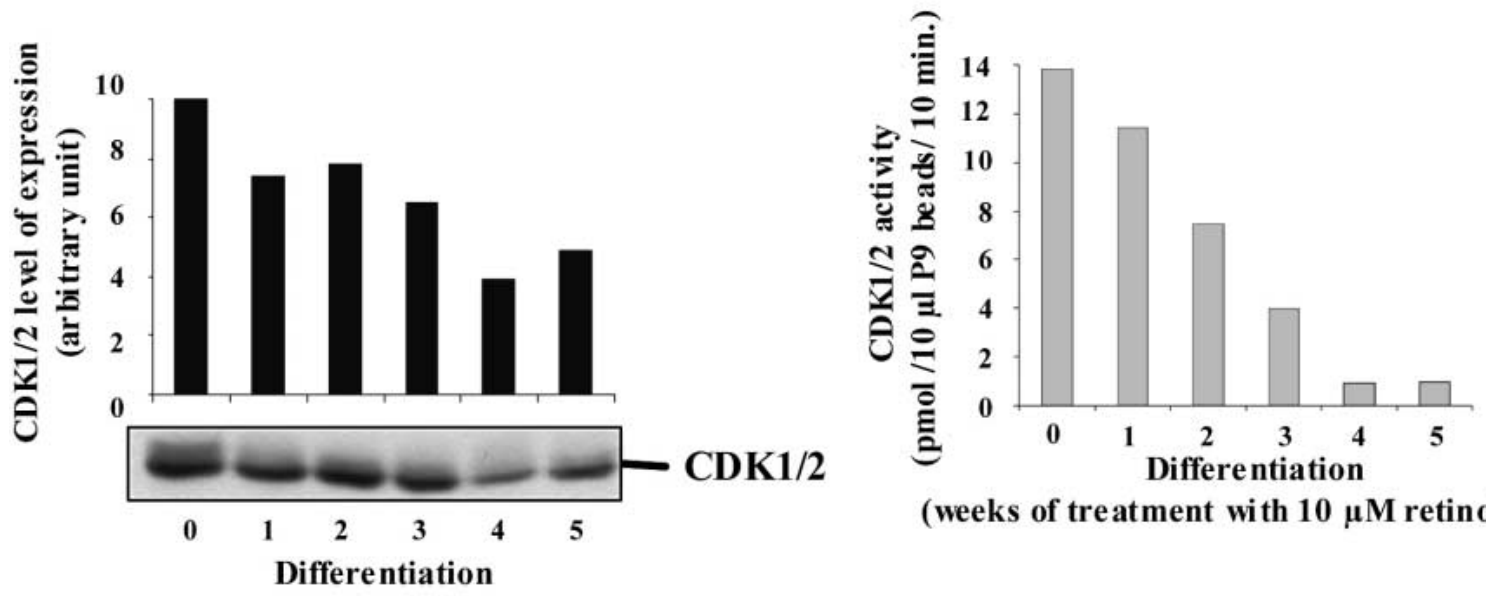

b (weeks of treatment with $10 \mu \mathrm{M}$ retinoic acid)

Fig. 2. Increase in CDK5 activity, p35 level and decrease in CDK $1 / 2$ activity during NT2 $\rightarrow$ hNT differentiation. NT2 cells were exposed to $10 \mu M$ retinoic acid for 5 weeks. Aliquots were withdrawn weekly and the status of CDK5/p35 (a) and CDK1/2 (b) was analyzed by Western blotting (left) and by kinase activity determination (right). Both CDK5 (purified on purvalanol-Sepharose) and p35 (50 $\mu \mathrm{g}$ of crude extract) levels were estimated by Western blotting and quantified (a, left) (representative of three independent experiments). The level of expression of CDK1/2 was estimated by Western blotting using anti-PSTAIRE antibodies (b, left). CDK 5 and CDK1/2 kinase activities were assayed using histone $\mathrm{H} 1$ as substrate following immunoprecipitation on anti-CDK5 agarose beads or affinity chromatography on $\mathrm{p} 9^{\mathrm{CKSh}} 1 \mathrm{~S}$ Sepharose, respectively (for CDK5, representative of three independent experiments and for CDK1/2, mean of three independent experiments).
GSK-3 $\beta 2$ (fig. 3a). In undifferentiated NT2 cells, GSK-3 $\alpha$ was more abundant than the $\beta$ isoforms in accordance with what has been observed in most tissues [15]. We note a 2.7-fold increase of the $\alpha$ isoform during the NT2 $\rightarrow \mathrm{hNT}$ differentiation. The level of expression of GSK-3 $\beta 1$ in- creased up to 6.9-fold after 3 weeks of treatment with retinoic acid. Then, it decreased slightly and remained stable at the late stages of neuronal differentiation. More striking was the change of expression of the GSK-3 32 isoform, recently identified as the product of an alternative splic- 


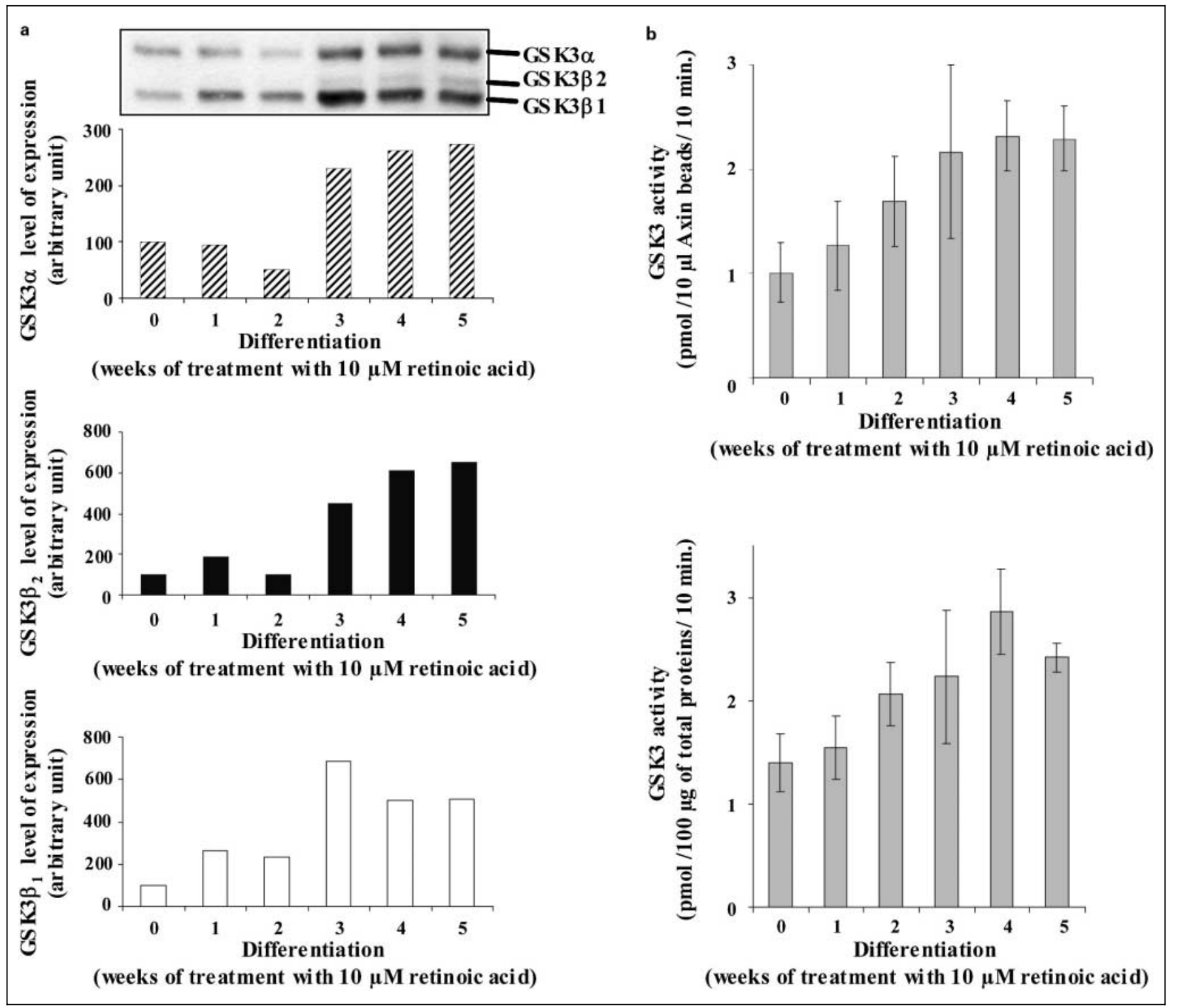

Fig. 3. Increase in GSK- 3 expression and activity during NT2 $\rightarrow$ hNT differentiation. NT2 cells were exposed to $10 \mu M$ retinoic acid for 5 weeks. Aliquots were withdrawn weekly. GSK-3 was purified on axin-Sepharose and the level of expression of each GSK-3 isoform was estimated following Western blotting and quantification (a, left)

(representative of six independent experiments). GSK-3 kinase activity was assayed using the GS-1 peptide as a substrate either following affinity chromatography on axin-Sepharose (b, top) or in crude extracts (b, bottom) (mean \pm SD of six different experiments).

ing of GSK-3 $\beta$ [8]. The GSK-3 $\beta 2$ isoform was hardly detectable in undifferentiated NT2 cells but its expression raised until the late stages of differentiation, reaching a final level 6.5-fold higher than that of undifferentiated cells.

We next monitored the changes of GSK-3 catalytic activity during neuronal NT2 differentiation (fig. 3b).

Only a modest increase, about 2.4-fold, of GSK-3 activity was detected following affinity purification on axin beads (fig. 3b, upper right panel). The regulation of GSK-3 catalytic activity by the axin peptide used to purify the kinase is not clearly established. It has been recently shown that full-length axin decreases GSK3 $\beta$-mediated tau phosphorylation, both in situ and in vitro [16]. Therefore, we 
a

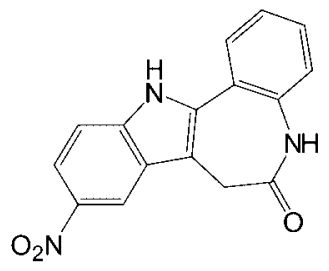

Alsterpaullone

CDK1/cyclinB

CDK5/p25

GSK-3

GSK-3
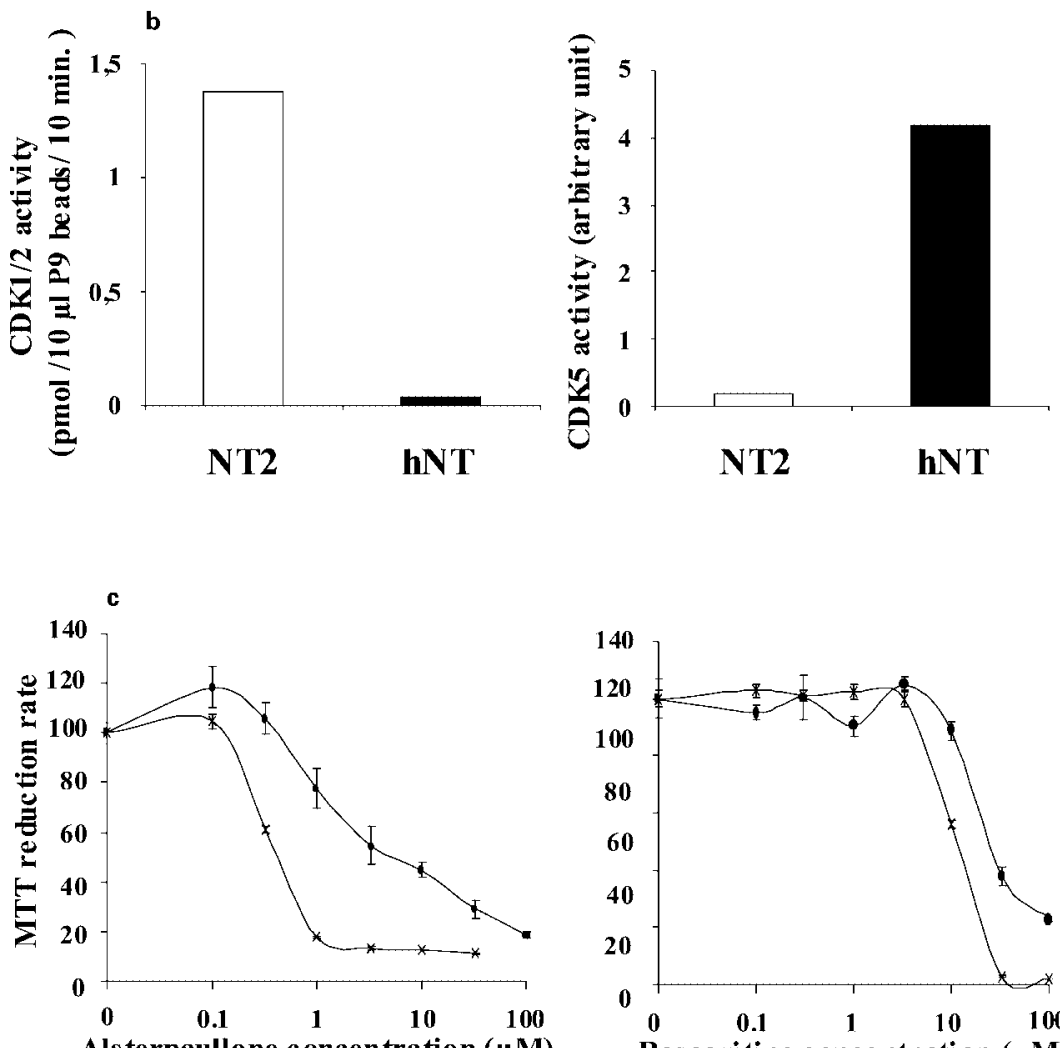

Alsterpaullone concentration $(\mu \mathrm{M})$

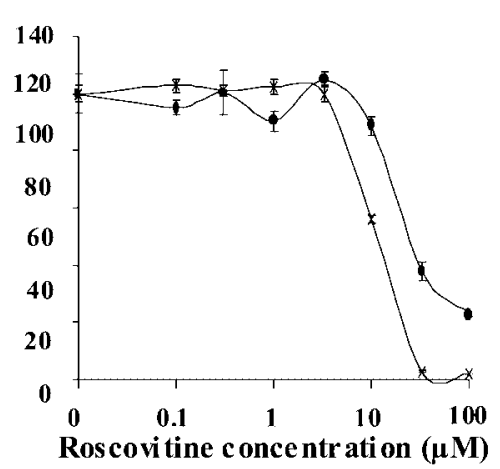

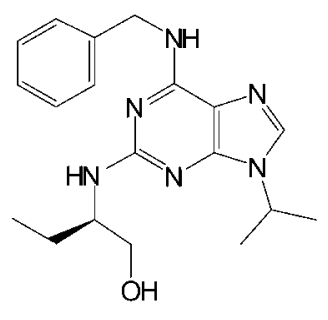

(R)-roscovitine

0.450

0.160

130.00<smiles>Nc1cc(N)cc(Cl)c1</smiles>

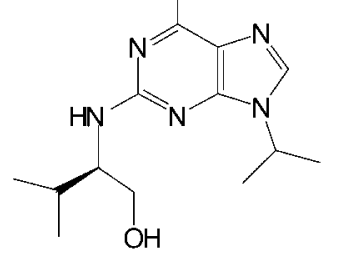

Aminopurvalanol

0.033

0.020

13.00
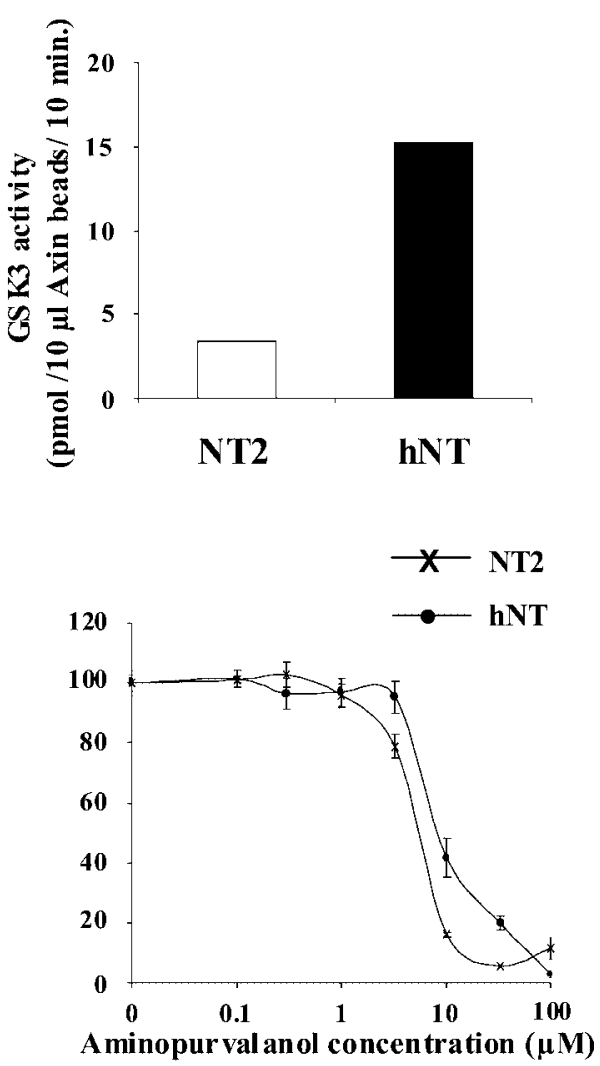
confirmed the changes of GSK-3 catalytic activity observed after purification of the enzyme by affinity chromatography on immobilized axin by monitoring the changes of GSK-3 catalytic activity during neuronal NT2 differentiation from crude lysates using GS-1, a specific substrate of GSK-3. Similar changes in GSK-3 activity were observed, validating the axin-beads approach used to purify GSK-3 (fig. 3b, lower right panel).

\section{Cellular Effects of Protein Kinases Inhibitors}

Deregulation of protein phosphorylation is a hallmark in number of neurodegenerative disorders. In Alzheimer's disease, GSK-3, CDK5 and other protein kinases like PKA, PKB, MARK or CK1 are responsible for the hyperphosphorylation of the Tau protein. Hyperphosphorylated Tau loses its ability to bind to microtubules and leads to cytoskeleton disruption. These protein kinases could thus constitute promising enzymatic targets for therapeutic inhibitors. We thus tested the effects of several well-characterized pharmacological inhibitors of GSK3 and/or CDKs, alsterpaullone, roscovitine and aminopurvalanol (fig. 4a). Both undifferentiated NT2 cells and differentiated hNT, postmitotic neurons exhibiting neurite extensions (after 5 weeks of culture in the presence of retinoic acid) were used. Determination of kinase activities showed drastic differences between NT2 and hNT cells, confirming earlier results (fig. 2, 3), namely a decrease of CDK $1 / 2$ and an increase in CDK 5 and GSK-3 activities (fig. 4b). Cells were thus exposed to various concentrations of the inhibitors for $24 \mathrm{~h}$ and cell viability estimated by the MTT reduction assay. Results clearly show a dose-dependent decrease of cell survival for each drug (fig. 4c). $\mathrm{GI}_{50}$ values for NT2 cells and hNT cells were, respectively, 0.4 and $5 \mu M$ (alsterpaullone), 11 and $30 \mu M$

Fig. 4. Cellular effects of some chemical kinases inhibitors on undifferentiated NT2 cells and post-mitotic hNT neurons. a Structure and kinase inhibitory properties of the inhibitors used. $\mathrm{IC}_{50}$ values for alsterpaullone, roscovitine and aminopurvalanol are from [30-33]. b Comparison of CDK1/2, CDK5 and GSK 3 kinase activities measured in NT2 and hNT cells ( 3 days after the second reseed) as described in previous figures. Means (GSK-3 and CDK1/2) and representative (CDK5) of three different experiments. c Dose-dependent effects of protein kinases inhibitors on the viability of NT2 and hNT cells. Exponentially growing NT2 and hNT cells (5 days after the second reseed) were exposed to several concentrations of alsterpaullone, roscovitine and aminopurvalanol during $24 \mathrm{~h}$. Cell viability was then estimated by the MTT reduction assay. Mean \pm SEM of five different experiments.

CDKs, GSK-3 and Neuronal

Differentiation (roscovitine) and 6 and $8 \mu M$ (aminopurvalanol). In hNT neurons, we observed neurite retraction (data not shown) at lethal doses.

\section{Discussion}

In the present study, we observed that, during neuronal differentiation, CDK5 becomes more and more active concomitant with increased $\mathrm{p} 35$ expression while cells are acquiring a neuronal cell phenotype. This confirms that CDK5 needs to be associated to p35 to exhibit a kinase activity $[17,18]$. CDK5 is a key element in the establishment of neural network [19] and in neuronal functions as it phosphorylates diverse substrates which have multifunctional roles in the nervous system [for review, see 2].

Cell differentiation implies cell cycle arrest in G1 phase. We observed a reduction of the activity of the cell cycle regulating kinases CDK1 and CDK2 during the differentiation process. Interestingly, the pattern observed is the exact opposite of the CDK5 activity pattern, suggesting a potential link between the two events. Our results confirm those found by Fu et al. [20] during NT2 differentiation using a cell aggregation method [21]. Here, we found that the pattern of activity and expression of CDKs is comparable whether the aggregation or the plating method is used.

GSK-3 activity increases moderately during neuronal differentiation of NT2 cells. This is accompanied by a slight increase of GSK-3 $\alpha$ expression. On the other hand, we observed a higher increase of GSK-3 $\beta 1$ expression concomitantly with the appearance of the recently identified GSK-3 $\beta 2$ isoform. These results are in agreement with the increase of GSK-3 expression that occurs during development of rat brain $[22,23]$. Interestingly, GSK-3 $\beta 1$ expression decreases significantly and GSK-3 activity stops increasing in the late stages of NT2 differentiation. This agrees with a high expression of GSK-3 $\beta$ during late embryonic and early postnatal development followed by a significant decrease in the adult brain after the major period of dendritic extension and synaptogenesis [22, 23]. GSK-3 is involved in the regulation of neuronal differentiation via the phosphorylation and frequently the inhibition of multiples substrates including proneural transcription factors such as neuroD [24]. It contributes to neurite outgrowth [25], axon branching, growth cone size and synaptogenesis regulation [6, 7]. The evolution of GSK-3 activity and expression can be paralleled with the expression of GSK-3 physiological substrates in neurons such as MAPs affecting microtubule stability. 
Our data indicate that the expression of the two isoforms of GSK-3 is regulated differently during neuronal differentiation. Although GSK-3 $\alpha$ and GSK-3 $\beta$ share a very similar structure, they do not have similar functions. Their expression is regulated spatially. We here show that their expression is also regulated temporally. Nonetheless, it appears that there is another level of regulation of GSK$3 \beta$ expression, at the transcription level, as alternative splicing, responsible of GSK-3 $\beta 2$ expression, occurs predominantly in nerve cells [26]. GSK-3 $\beta 2$ has possibly specific neuronal functions that have to be discriminated from those of GSK-3 $\beta 1$.

The elucidation of the functional differences between the several isoforms may contribute to improve the therapeutic use of GSK-3 inhibitors. As CDKs and GSK-3 play crucial roles in neuronal differentiation and are deregulated in neurodegenerative disorders such as Alzheimer's disease, the characterization of some specific inhibitors constitutes a promising therapeutic approach. The purines, aminopurvalanol and roscovitine, exhibit similar antiproliferative effects on NT2 viability or hNT viability. It seems that the main targets of the compounds are different according to the state of differentiation: in the undifferentiated state, CDK1 and 2 are inhibited, preventing self-renewal, whereas in hNT, CDK5 is probably the main target leading to cytoskeletal disruption. In comparison, there is a 10 -fold difference between $\mathrm{GI}_{50}$ of alsterpaullone on NT2 and hNT. Alsterpaullone has a very high efficiency on GSK-3 in vitro. A chromatography approach revealed that GSK-3 was the main intracellular target of the paullones [27]. GSK-3 contributes to neuronal death and destabilizes the cytoskeleton when upregulated. As GSK-3 is not a target of purines, we suggest that the inhibition of GSK-3 in hNT treated with alsterpaullone is responsible of the 10 -fold increase of the $\mathrm{GI}_{50}$.

A recent study showed that treatment of neuronal stem cells with small compounds active on GSK-3 $\beta$ leads to neuronal differentiation showing the crucial role of GSK3 presumably played in inhibiting neuronal differentiation [28]. Using CDKs and GSK-3 inhibitors during differentiation could help elucidating the involvement of these kinases in this process. Although it is already known that the activation or inhibition of GSK-3 and/or CDKs are crucial events in this process, whether they are initiators or effectors of the phenomenon remains to be elucidated.

\section{Acknowledgements}

This work has been supported by the 'Conseil Régional de Bretagne' and the 'Société de Secours des Amis des Sciences' (M.G.). The antibody anti-NSE was a kind gift of A. Delacourte. This research was supported by the Ministère de la Recherche/INSERM/CNRS 'Molécules et Cibles Thérapeutiques' Programme.

\section{References}

1 Cohen P: The origins of protein phosphorylation. Nat Cell Biol 2002;4:E127-130.

2 Paglini G, Caceres A: The role of the Cdk5-p35 kinase in neuronal development. Eur J Biochem 2001;268:1528-1533.

3 Dhavan R, Tsai LH: A decade of CDK5. Nat Rev Mol Cell Biol 2001;2:749-759.

4 Embi N, Rylatt DB, Cohen P: Glycogen synthase kinase- 3 from rabbit skeletal muscle. Separation from cyclic-AMP-dependent protein kinase and phosphorylase kinase. Eur J Biochem 1980;107:519-527.

5 Doble BW, Woodgett JR: GSK-3: Tricks of the trade for a multi-tasking kinase. J Cell Sci 2003;116:1175-1186.

6 Hall AC, Lucas FR, Salinas PC: Axonal remodeling and synaptic differentiation in the cerebellum is regulated by WNT-7a signaling. Cell 2000; 100:525-535.

7 Goold RG, Gordon-Weeks PR: Microtubuleassociated protein $1 \mathrm{~B}$ phosphorylation by glycogen synthase kinase 3 beta is induced during PC12 cell differentiation. J Cell Sci 2001;114: 4273-4284.
8 Mukai F, Ishiguro K, Sano Y, Fujita SC: Alternative splicing isoform of tau protein kinase I/ glycogen synthase kinase 3beta. J Neurochem 2002;81(5):1073-1083

9 Pleasure SJ, Lee VM: NTera 2 cells: A human cell line which displays characteristics expected of a human committed neuronal progenitor cell. J Neurosci Res 1993;35:585-602.

10 Pleasure SJ, Page C, Lee VM: Pure, postmitotic, polarized human neurons derived from NTera 2 cells provide a system for expressing exogenous proteins in terminally differentiated neurons. J Neurosci 1992;12:1802-1815.

11 Sanchez C, Diaz-Nido J, Avila J: Phosphorylation of microtubule-associated protein 2 (MAP2) and its relevance for the regulation of the neuronal cytoskeleton function. Prog Neurobiol 2000;61:133-168.

12 Tsai LH, Takahashi T, Caviness VS, Harlow E: Activity and expression pattern of cyclin-dependent kinase 5 in the embryonic mouse nervous system. Development 1993;119:10291040 .
13 Azzi L, Meijer L, Ostvold A, Lew J, Wang J: Purification of a 15-kDa cdk4- and cdk5-binding protein. J Biol Chem 1994;269:1327913288.

14 Primot A, Baratte B, Gompel M, Borgne A, Liabeuf S, Romette JL, et al: Purification of GSK-3 by affinity chromatography on immobilized axin. Protein Expr Purif 2000;20:394404.

15 Lau KF, Miller CC, Anderton BH, Shaw PC: Expression analysis of glycogen synthase kinase-3 in human tissues. J Pept Res 1999; 54(1):85-91.

16 Stoothoff WH, Bailey CD, Mi K, Lin SC, Johnson GV: Axin negatively affects tau phosphorylation by glycogen synthase kinase 3beta. J Neurochem 2002;83:904-913.

17 Tsai LH, Delalle I, Caviness VS, Chae T, Harlow E: p35 is a neural-specific regulatory subunit of cyclin-dependent kinase 5. Nature 1994;371:419-423. 
18 Ko J, Humbert S, Bronson RT, Takahashi S, Kulkarni AB, Li E, et al: p35 and p39 are essential for cyclin-dependent kinase 5 function during neurodevelopment. J Neurosci 2001;21: 6758-6771.

19 Nikolic M, Dudek H, Kwon YT, Ramos YF, Tsai LH: The cdk5/p35 kinase is essential for neurite outgrowth during neuronal differentiation. Genes Dev 1996;10:816-825.

$20 \mathrm{Fu}$ WY, Wang JH, Ip NY: Expression of Cdk5 and its activators in NT2 cells during neuronal differentiation. J Neurochem 2002;81:646654.

21 Cheung WM, Fu WY, Hui WS, Ip NY: Production of human CNS neurons from embryonal carcinoma cells using a cell aggregation method. Biotechniques 1999;26:946-948, 950-952, 954.

22 Takahashi M, Tomizawa K, Kato R, Sato K, Uchida T, Fujita SC, et al: Localization and developmental changes of tau protein kinase I/ glycogen synthase kinase- 3 beta in rat brain. J Neurochem 1994;63:245-255.

23 Leroy K, Brion JP: Developmental expression and localization of glycogen synthase kinase3beta in rat brain. J Chem Neuroanat 1999;16: 279-293.
24 Marcus EA, Kintner C, Harris W: The role of GSK3beta in regulating neuronal differentiation in Xenopus laevis. Mol Cell Neurosci 1998; 12:269-280.

25 Takahashi M, Yasutake K, Tomizawa K: Lithium inhibits neurite growth and tau protein kinase I/glycogen synthase kinase-3beta-dependent phosphorylation of juvenile tau in cultured hippocampal neurons. J Neurochem 1999;73:2073-2083.

26 Schaffer B, Wiedau-Pazos M, Geschwind DH: Gene structure and alternative splicing of glycogen synthase kinase 3 beta (GSK-3beta) in neural and non-neural tissues. Gene 2003;302: 73-81.

27 Knockaert M, Wieking K, Schmitt S, Leost M, Grant KM, Mottram JC, et al: Intracellular Targets of Paullones: Identification following affinity purification on immobilized inhibitor. J Biol Chem 2002;277:25493-25501.

28 Ding S, Wu TYH, Brinker A, Peters EC, Hur W, Gray NS, Schultz PG: Synthetic small molecules that control stem cell fate. PNAS 2003: 0732087100
29 Mosmann T: Rapid colorimetric assay for cellular growth and survival: Application to proliferation and cytotoxicity assays. J Immunol Methods 1983;65:55-63.

30 Chang YT, Gray NS, Rosania GR, Sutherlin DP, Kwon S, Norman TC, et al: Synthesis and application of functionally diverse 2,6,9-trisubstituted purine libraries as $\mathrm{CDK}$ inhibitors. Chem Biol 1999;6:361-375.

31 Leost M, Schultz C, Link A, Wu YZ, Biernat J, Mandelkow EM, et al: Paullones are potent inhibitors of glycogen synthase kinase-3beta and cyclin-dependent kinase 5/p25. Eur J Biochem 2000;267:5983-5994.

32 Meijer L, Borgne A, Mulner O, Chong JP, Blow $\mathrm{JJ}$, Inagaki $\mathrm{N}$, et al: Biochemical and cellular effects of roscovitine, a potent and selective inhibitor of the cyclin-dependent kinases cdc2, cdk2 and cdk5. Eur J Biochem 1997;243:527536.

33 Schultz C, Link A, Leost M, Zaharevitz DW, Gussio R, Sausville EA, et al: Paullones, a series of cyclin-dependent kinase inhibitors: Synthesis, evaluation of CDK1/cyclin B inhibition, and in vitro antitumor activity. $\mathrm{J}$ Med Chem 1999;42:2909-2919. 